Supplement of The Cryosphere, 15, 407-429, 2021 https://doi.org/10.5194/tc-15-407-2021-supplement C Author(s) 2021. This work is distributed under the Creative Commons Attribution 4.0 License.

(c) (1)

Supplement of

\title{
Observing traveling waves in glaciers with remote sensing: new flexible time series methods and application to Sermeq Kujalleq (Jakobshavn Isbra), Greenland
}

Bryan Riel et al.

Correspondence to: Bryan Riel (briel@mit.edu)

The copyright of individual parts of the supplement might differ from the CC BY 4.0 License. 


\section{Supplement}

\section{Supplemental Figures}
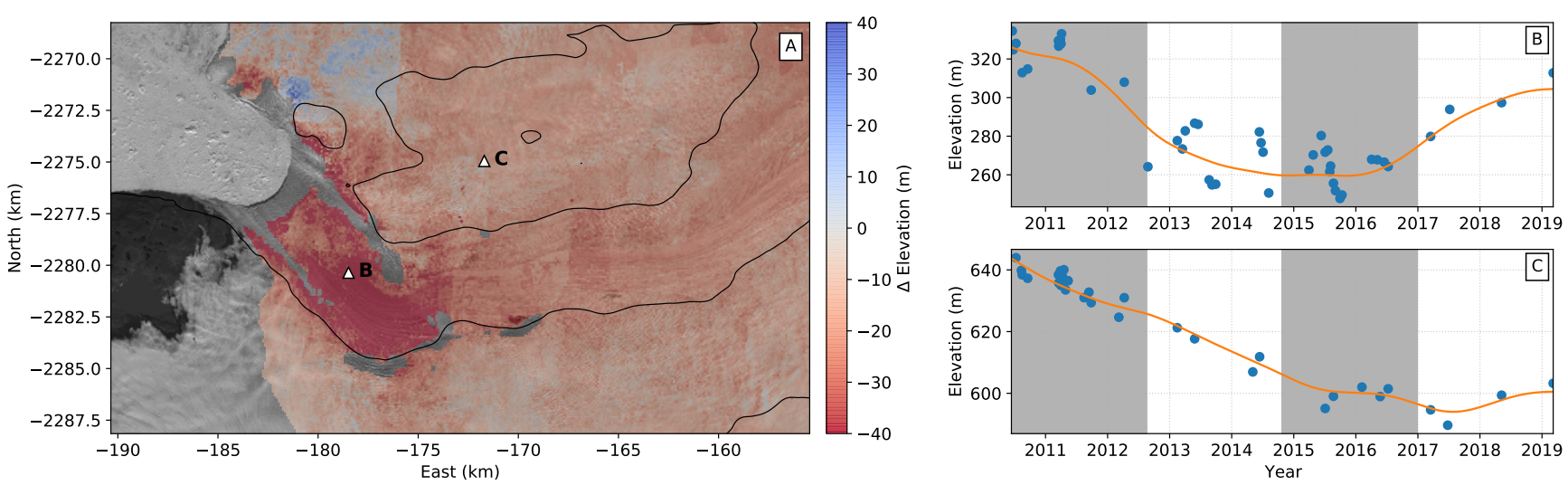

Figure S1. Elevation change image and time series. (A) Elevation change from June 2010 to September 2012 (same time span as Figure 6 in main text). Black contours correspond to $0 \mathrm{~m}$ bed elevation. Markers correspond to location of extracted timeseries in (B) and (C), where the blue markers correspond to the raw ArcticDEM data and the orange lines correspond to long-term timeseries fits. Alternating gray and white regions in (B) and (C) correspond to the time periods used for computing elevation and velocity differences in Figure 6 in the main text. Until 2018, note the steady lowering of the ice surface for point (C) compared to point (B) which is more affected by glacier dynamics. 


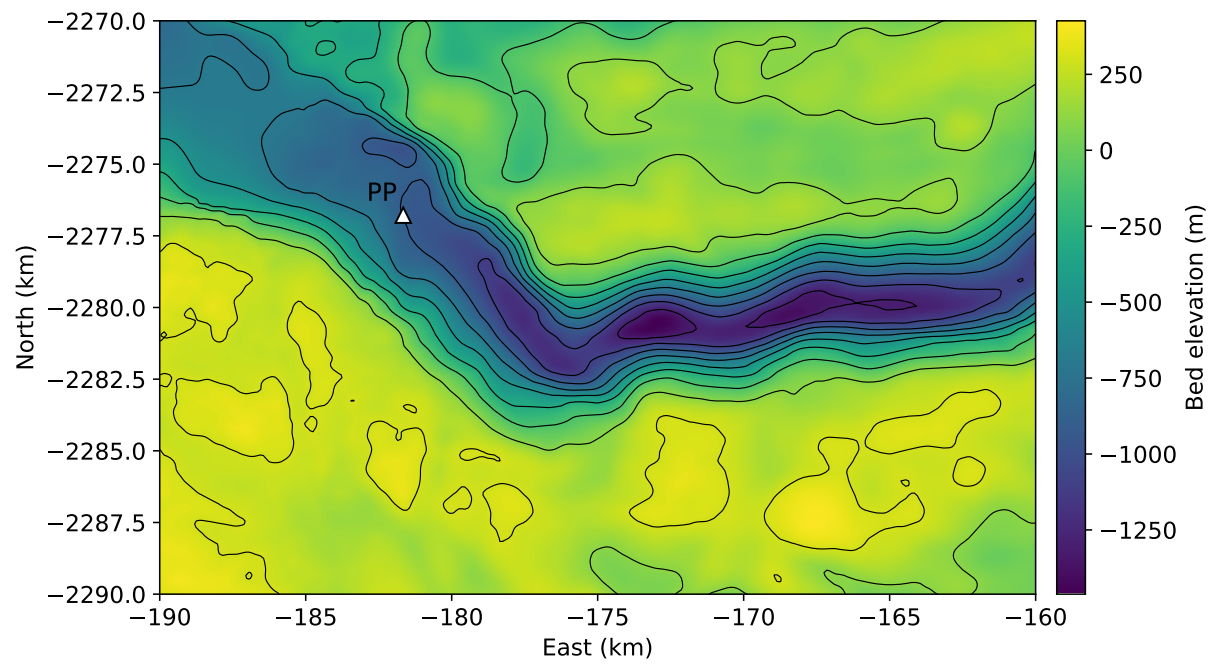

Figure S2. Basal topography at Jakobshavn Isbræ from BedMachine V3 (Morlighem et al., 2017). Contours are at $200 \mathrm{~m}$ intervals. Marker corresponds to the pinning point location referenced in the main text (see Figure 4).

\section{References}

Morlighem, M., Williams, C. N., Rignot, E., An, L., Arndt, J. E., Bamber, J. L., Catania, G., Chauché, N., Dowdeswell, J. A., Dorschel, B., Fenty, I., Hogan, K., Howat, I., Hubbard, A., Jakobsson, M., Jordan, T. M., Kjeldsen, K. K., Millan, R., Mayer, L., Mouginot, J., Noël, B. P. Y., O’Cofaigh, C., Palmer, S., Rysgaard, S., Seroussi, H., Siegert, M. J., Slabon, P., Straneo, F., van den Broeke, M. R., Weinrebe, W., Wood, M., and Zinglersen, K. B.: BedMachine v3: Complete Bed Topography and Ocean Bathymetry Mapping of Greenland From Multibeam Echo Sounding Combined With Mass Conservation., Geophysical Research Letters, 44, 11 051-11 061, https://doi.org/10.1002/2017GL074954, 2017. 